In conclusion, CSF rhinorrhoea can occur more than 20 years after head trauma, and thus the patient remains at risk of developing meningitis for the rest of his life. Surgical repair of the fistula is mandatory, as spontaneous closure is unlikely. ${ }^{12-17}$ It is worth mentioning that meningitis can occur whatever the duration of CSF rhinorrhoea ( 3 years in this case). It is also important to remember that antibiotics prescribed before the repair is completed can select for antibiotic-resistant organisms, which may prove difficult to treat should they gain access to the CSF. The possibility of a CSF leak should be considered in any patient with a chronic clear nasal discharge. The patient should be questioned in detail about any previous head trauma, no matter when it occurred. The nasal fluid should be analysed with sensitive immunochemical methods for the presence of CSF-specific proteins, especially the beta-2transferrin. ${ }^{18}$ Finally, in patients with Gram-negative bacillary meningitis, in the absence of classical risk factors, the possibility of a CSF leak should be considered, as well as any associated prior antibiotic treatment.

\section{References}

1 Campbell JR, Diacovo T, Baker CJ. Serratia marcescens meningitis in neonates. Pediatr Infect Dis J 1992; 11: 881-886.

2 Unhanand M, Mustafa MM, McCracken GH, Nelson JD. Gramnegative enteric bacillary meningitis: a twenty-one-year experience. I Pediatr 1993; 122: 15-21.

3 Gower DJ, Barrows AA, Kelly DL, Pegram S. Gram-negative bacillary meningitis in the adult: review of 39 cases. South Med J 1986; 79: 1499-1502.

4 Mangi RJ, Quintiliani R, Andriole VT. Gram-negative bacillary meningitis. Am J Med 1975; 59: 829-836.
5 Cherubin CE, Marr JS, Sierra MF, Becker S. Listeria and Gramnegative bacillary meningitis in New York City, 1972-1979. Frequent causes of meningitis in adults. Am J Med 1981; 71: 199-209.

6 Berk SL, McCabe WR. Meningitis caused by Gram-negative bacilli. Ann Intern Med 1980; 93: 253-260.

7 Durand ML, Calderwood SB, Weber DJ et al. Acute bacterial meningitis in adults. A review of 493 episodes. $N$ Engl J Med 1993; 328: 21-28.

8 Calhoun KH, Weiner RL, Theilen FW, Quinn FB, Stiernberg CM. Cerebrospinal fluid rhinorrhoea 41 years after injury. Otolaryngol Head Neck Surg 1988; 98: 90-91.

9 Hingorani RK. Cerebrospinal fluid rhinorrhoea. I Laryngol Otol 1971; 85: 99-1006.

10 Okada J, Tsuda T, Takasugi S, Nishida K, Toth Z, Matsumoto K. Unusually late onset of cerebrospinal fluid rhinorrhoea after head trauma. Surg Neurol 1991; 35: 213-217.

11 Crawford C, Kennedy N, Weir WRC. Cerebrospinal fluid rhinorrhoea and Haemophilus influenzae meningitis 37 years after a head injury. J Infect 1994; 28: 93-97.

12 Kaufman BA. Tunkel AR, Pryor JC, Dacey RG. Meningitis in the neurosurgical patient. Infect Dis Clin North Am 1990; 4: 677-701.

13 Eljamel MS, Foy PM. Acute traumatic CSF fistulae, the risk of intracranial infection. Br J Neurosurg 1990; 4: 381-385.

14 Eljamel MS. Fractures of the middle third of the face and cerebrospinal fluid rhinorrhoea. Br J Neurosurg 1994; 8: 289-93.

15 Eljamel MSM, Foy PM. Post-traumatic CSF fistulae, the case for surgical repair. Br J Neurosurg 1990; 4: 479-83.

16 Griffith HB. CSF fistula and the surgeon. Br J Neurosurg 1990; 4: 369-371.

17 Jamieson KG, Yelland JDN. Surgical repair of the anterior fossa because of rhinorrhoea, aerocele or meningitis. J Neurosurg 1973; 39: $328-331$.

18 Fransen P. Sindic CJM, Thauvoy C, Laterre C. Stroobandt G. Highly sensitive detection of beta-2-transferrin in rhinorrhoea and otorrhea as a marker of cerebrospinal fluid (CSF) leakage. Acta Neurochir (Wien) 1991; 109: 98-101.

\title{
Haemophilus aphrophilus Bacteraemia Complicated with Vertebral Osteomyelitis and Spinal Epidural Abscess in a Patient with Liver Cirrhosis
}

\author{
C. C. Hung ${ }^{1}$, P. R. Hsueh ${ }^{2}$, Y. C. Chen ${ }^{1}$, C. T. Fang ${ }^{1}$, S. C. Chang ${ }^{* 1}$, K. T. Luh ${ }^{2}$ and \\ W. C. Hsieh'
}

${ }^{1}$ Section of Infectious Diseases, Department of Internal Medicine and ${ }^{2}$ Department of Laboratory Medicine, National Taiwan University Hospital, 7 Chung-Shan South Road, Taipei, Taiwan

\begin{abstract}
Haemophilus aphrophilus is rarely implicated as an aetiology of spinal epidural abscess. A 73-year-old woman with liver cirrhosis who developed $H$. aphrophilus bacteraemia complicated with vertebral osteomyelitis and spinal epidural abscess is presented. Without surgical decompression, she was successfully treated with cefotaxime for 3 weeks, followed by maintenance with ciprofloxacin for another 10 weeks. The clinical features of eight previously reported cases of vertebral osteomyelitis without epidural abscess due to $H$. aphrophilus are reviewed.
\end{abstract}

\section{Introduction}

While Haemophilus aphrophilus is a normal component of oral flora and can be recovered from gingival scrapings and inter-

* Address correspondence to: Dr S. C. Chang. Accepted for publication 10 January 1997. dental material with a selective medium, ${ }^{1}$ it has been an infrequent aetiology of human infections. ${ }^{2}$ Reported infections due to $H$. aphrophilus include endocarditis, bacteraemia, brain abscess, meningitis, pneumonia, osteomyelitis, meningitis, dental abscess, sinusitis, and soft tissue infections. ${ }^{2-4}$ Vertebral osteomyelitis due to $H$. aphrophilus is uncommon, and to our knowledge, only eight cases have been described previously in 
the English literature. ${ }^{5-12}$ Spinal epidural abscess due to $H$. aphrophilus has not been reported. Here, we present an elderly female with liver cirrhosis who developed $H$. aphrophilus bacteraemia complicated with vertebral osteomyelitis and spinal epidural abscess, and was successfully treated with antibiotics without surgical intervention.

\section{Case Report}

A 73-year-old woman was admitted with a 2-day history of fever. She had had liver cirrhosis for 10 years but had been otherwise well. One week before admission, she had a fall from a height of three stairs, and had suffered from back pain with radiation to the right lower limb since then. Two days prior to admission high fever, numbness and weakness of the right lower extremity developed. There were no respiratory symptoms, dysuria, skin abrasion from the fall, or abdominal symptoms. She denied undergoing previous dental or urogenital procedures. On examination, the body temperature was $37.9^{\circ} \mathrm{C}$, pulse rate $110 / \mathrm{min}$ and $\mathrm{BP} 120 / 70 \mathrm{mmHg}$. Consciousness was clear. She had dental crown but there was no evidence of periodontitis. Neither tonsillar infection nor paranasal percussion tenderness were noted. Chest examination was negative. Cardiac examination revealed a grade $3 / 6$ pansystolic murmur at the left lower sternal border. The liver was not enlarged, while spleen tip was palpable. Percussion tenderness was elicited along spinous processes of lumbar spines and right flank area. Muscle power of the right lower leg was diminished, but deep tendon reflexes were not increased. The plantar responses were flexor bilaterally. Co-ordination, proprioceptive and sphincter functions were preserved. Hypoaesthesia was noted over the saddle area. WBC count was $5.0 \times 10^{9} / 1$ with $12 \%$ band forms and $81 \%$ neutrophils, haemoglobin $9.5 \mathrm{~g} / 1$ and platelet count $33 \times 10^{9} / \mathrm{l}$. Serum biochemistry showed albumin $3.0 \mathrm{~g} / \mathrm{dl}$, globulin $3.6 \mathrm{~g} / \mathrm{dl}$, total bilirubin $54.7 \mu \mathrm{mol} / \mathrm{l}$, aspartate aminotransferase $106 \mathrm{IU} / \mathrm{l}$, alanine aminotransferase $75 \mathrm{IU} / \mathrm{I}$ and alkaline phosphatase $159 \mathrm{IU} / \mathrm{l}$. ESR was $110 \mathrm{~mm} /$ $\mathrm{h}$ and C-reactive protein $6.35 \mathrm{mg} / \mathrm{dl}$. Radiographs of thoracic and lumbar spines did not show osteolytic lesions or compression fractures. Three phase bone imaging revealed increased tracer uptake at the fourth (L4) and fifth (L5) lumbar spines. Two sets of blood culture obtained at entry both yielded Gramnegative coccobacilli after 4 days of incubation. The organism grew well by subculture onto sheep blood agar, chocolate agar, and trypticase soy agar at $35-37^{\circ} \mathrm{C}$ in $5-10 \% \mathrm{CO}_{2}$ for $24 \mathrm{~h}$. The organism was not $\mathrm{V}$ - or $\mathrm{X}$-factor dependent and exhibited a positive porphyrin reaction, characteristics which were in agreement with those of $H$, aphrophilus. Minimum inhibitory concentrations (MICs) of antimicrobial agents against this isolate were determined by means of the $\mathrm{E}$ test (PDM Epsilometer, $\mathrm{AB}$ Biodisk, Solna, Sweden) on Mueller-Hinton agar supplemented with $5 \%$ sheep blood agar. Haemophilus influenzae ATCC 49274 was used as the control strain. Ampicillin ( $M I C=0.25 \mathrm{mg}$ / I), cefotaxime (MIC $=0.12 \mathrm{mg} / \mathrm{l})$, aztreonam $(\mathrm{MIC}=0.25 \mathrm{mg} / \mathrm{l})$ and ciprofloxacin (MIC $=0.12 \mathrm{mg} / \mathrm{l}$ ) were shown to be active against the isolate. Erythromycin $(\mathrm{MIC}=16 \mathrm{mg} / \mathrm{l})$ and clarithromycin ( $\mathrm{MIC}=32 \mathrm{mg} / \mathrm{l}$ ) had poor activities against this organism. $\beta$-lactamase activity of this isolate, as checked by a cefinase disk (BBL, Microbiology System, Cockeysille, MD, U.S.A.), was negative.

Transthoracic and transoesophageal echocardiography both failed to detect vegetation or intracardiac thrombi. Because of

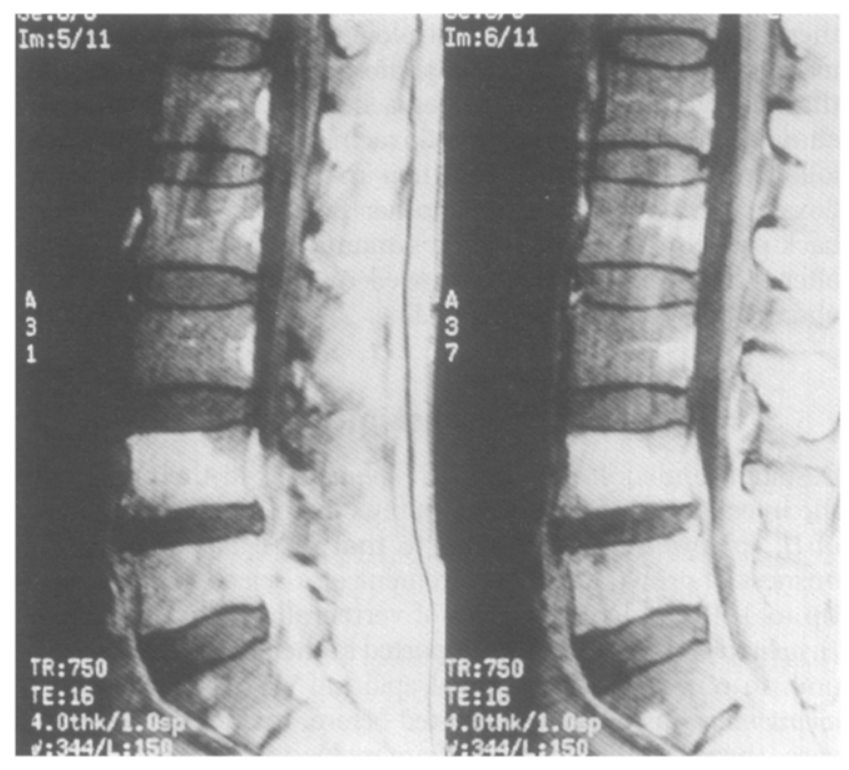

Figure 1. MRI of the spine after gadolinium enhancement, showing osteomyelitis of the fourth (L4) and fifth (L5) lumbar spines, prevertebral abscess and epidural abscess extending from $L 1$ to the sacrum.

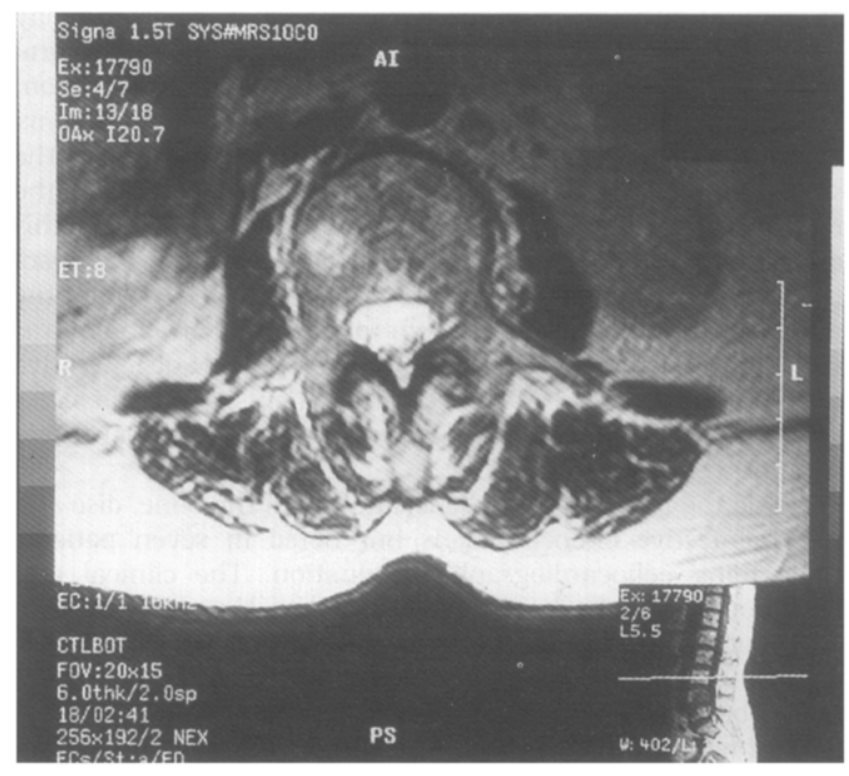

Figure 2. Enhanced MRI at the level of the third lumbar spine, showing compressed thecal sac and impingement of the spinal cord.

persistent back pain, an enhanced magnetic resonance imaging (MRI) scan was performed to reveal abnormal signal intensity, with enhancement of $\mathrm{L} 4$ and $\mathrm{L} 5$ and anterolateral paraspinal region around L3 to L5. Prominent dural and epidural enhancement were detected (Fig, 1). The thecal sac was compressed (Figs 1 and 2). With the diagnosis of vertebral osteomyelitis, spinal dural and epidural abscess, antibiotic was started with cefotaxime $1.0 \mathrm{~g}, \mathrm{q} 4 \mathrm{~h}$. Surgical or computed tomography (CT)-guided drainage was suggested, but was not accepted by the patient. The clinical response to antibiotic 
therapy was slow, though neurological symptoms did not deteriorate. After 3 weeks of cephalosporin therapy, worsening thrombocytopenia and leucopenia developed. Cefotaxime was changed to intravenous ciprofloxacin $300 \mathrm{mg} \mathrm{q} 12 \mathrm{~h}$ for the following 14 days. She was then maintained on oral ciprofloxacin $500 \mathrm{mg} \mathrm{q} 12 \mathrm{~h}$ for another 8 weeks. She was free of back pain during follow-up for 4 months. Repeated MRI scans after 4 months of therapy showed resolution of the epidural abscess and vertebral osteomyelitis.

\section{Discussion}

Despite the ubiquitousness of $H$. aphrophilus in the oral cavity, the infection is infrequent, probably due to the lower virulence of $H$. aphrophilus as compared to that of $H$. influenzae, fastidiousness of growth, and requirement of a selective medium. ${ }^{1.13}$ Up to 1995 , only eight cases of vertebral osteomyelitis due to $H$. aphrophilus has ever been reported in the English literature ${ }^{5-12}$ and, to our knowledge, spinal epidural abscess caused by $H$. aphrophilus has not been reported before. Including the present case, there are five men and four women with a mean age of 54 years who have presented with vertebral osteomyelitis due to $H$. aphrophilus (Table I). Underlying diseases have been described in five patients: polyarthritis, cirrhosis, diabetes mellitus, and sciatica. The predisposing factors to vertebral osteomyelitis include lip laceration ${ }^{6}$ and penetrating injury such as epidural catheterization ${ }^{5}$ or myelography. ${ }^{7}$ The bacteria may have been introduced directly to infect the disc and vertebral bodies through the lumbar puncture. ${ }^{5,7}$ Following lip laceration, ${ }^{6}$ trivial skin breaks, ${ }^{10}$ or dental procedures, ${ }^{10,12}$ bacteraemia develops with subsequent haematogenous dissemination to the spine. In patients without evident predisposing factors, the mouth may still be a likely source of infection due to this organism. ${ }^{1}$ Daily dental cleansing or flossing may cause bacteraemia, ${ }^{14}$ and the bacteria were not cleared efficiently by the reticuloendothelial system as our patient had liver cirrhosis with impaired phagocytosis. With comorbidity of degenerative bone and joint diseases in the elderly patients, ${ }^{15} \mathrm{H}$. aphrophilus may be seeded to vertebral bodies and cause vertebral osteomyelitis.

While the bacteria could be isolated from the bone, disc and blood, infective endocarditis is not noted in seven patients undergoing echocardiographic evaluation. The clinical presentation of vertebral osteomyelitis due to $H$. aphrophilus can be subacute to chronic $c^{5-10.12}$ or acute, ${ }^{6,11}$ and is frequently confusing, as patients may have pre-existing sciatica. ${ }^{5,7-9,12}$ Lower back pain involving lower thoracic and lumbar spines with or without fever is the most common initial manifestation. Following vertebral osteomyelitis, the clinical course may be complicated with paravertebral and psoas muscle abscess, ${ }^{5,7}$ or, in our patient, with spinal epidural abscess. The spinal epidural abscess impinges on the nerve root or spinal cord and therefore causes her motor or sensory deficits.

The initial correct diagnosis of vertebral osteomyelitis and spinal epidural abscess is often difficult, ${ }^{15.16}$ and delayed diagnosis and treatment may result in irreversible neurological deficits or fatalities. ${ }^{15-17}$ In our patient, the diagnosis was prompted by the presentation of fever, persistent back pain and the associated neurological symptoms and signs..$^{15,16.18}$ With the aid of gadolinium-enhanced MRI, ${ }^{17}$ early diagnosis, clear definition of extents and serial follow-ups are possible and potential contamination during diagnostic myelography or lumbar puncture at spinal levels of active infection can be avoided.
To treat spinal epidural abscess, immediate surgical decompression has been advocated in order to reduce the morbidity and mortality, ${ }^{15}$ especially in patients with worsening neurological deficits, ${ }^{5.12}$ persistent severe pain, increasing body temperature, WBC count, ${ }^{19}$ or complication of psoas abscess. ${ }^{5,}$ ${ }^{7}$ In certain patients without neurological deficits or without progressing deficits, and with clinical response to antibiotics in careful daily evaluations, ${ }^{19}$ or, as in our patient, with a pathogen with lower pathogenicity, antibiotic therapy can be successful.

Clinical isolates of $H$. aphrophilus have been demonstrated to be susceptible to penicillin, ampicillin, and cephalosporins by the disk diffusion susceptibility testings. ${ }^{5,10}$ The in vitro activities of penicillin, ampicillin, third generation cephalosporins and ciprofloxacin against clinical isolates of $H$. aphrophilus, as determined by the microdilution susceptibility test, are excellent, ${ }^{4-6,8,10}$ while those of oxacillin, erythromycin, and aminoglycosides are poor. ${ }^{4,6}$ By using the E test, we also demonstrated similar MIC patterns of our isolate to those obtained by using the microdilution method. With or without the help of surgical intervention, with administration of antibiotics based on these in vitro susceptibility tests, successful treatment of $H$. aphrophilus vertebral osteomyelitis without relapse can be achieved. ${ }^{5-8,10,12}$ Clinical failure to third generation cephalosporin and resistance of $H$. aphrophilus to ampicillin, cefuroxime, cefotaxime, and ceftazadime may occur, however, without producing $\beta$-lactamase. ${ }^{12}$ Marked inoculum effect has been observed, and clinical improvement is not achieved until ciprofloxacin replaces the cephalosporin. ${ }^{12}$

In summary, this unique case of $H$. aphrophilus bacteraemia complicated with spinal epidural abscess and vertebral osteomyelitis not only serves to expand the spectrum of bacteria causing spinal epidural abscess, but also highlights the possibility that medical therapy can be successful in carefully observed patients without neurological progression.

\section{References}

1 Kraut MS, Atterbery HR, Finegold SM, Sutter VL. Detection of Haemophilus aphrophilus in the human oral flora with a selective medium. J Infect Dis 1972; 126: 189-192.

2 Page MI. King EO. Infections due to Actinobacillus actinomycetacomitans and Hemophilus aphrophilus. N Engl J Med 1966; 275: 181-188.

3 Elster SK. Mattes LM, Meyers BR, Jurado RA. Hemophilus aphrophilus endocarditis: review of 23 cases. Am J Cardiol 1975; 35: 72-79.

4 Bieger RC, Brewer NS, Washington JA. Haemophilus aphrophilus: a microbiologic and clinical review and report of 42 cases. Medicine 1978: 75: 345-355.

5 Farrington M, Eykyn SJ, Walker M, Warren RE. Vertebral osteomyelitis due to coccobacilli of the HB group. Br Med I 1983; 287: 1658 .

6 Ho JL, Soukiasian S, Oh WH, Snydman DR. Hemophilus aphrophilus osteomyelitis. Am J Med 1984; 76: 159-161.

7 Petty BG, Burrow CR, Robinson RA, Bulkley GB. Hemophilus aphrophilus meningitis followed by vertebral osteomyelitis and suppurative psoas abscess. Am J Med 1985; 78: 159-162.

8 Houssiau FA, Huaux JP, De Deuxchaisnes CN. Haemophilus aphrophilus: a rare pathogen in vertebral osteomyelitis. Ann Rheum Dis 1987; 46: 248-250.

9 Gribble MJ, Hunter T. Hemophilus aphrophilus vertebral osteomyelitis: a case report and literature review. Diag Microbiol Infect Dis 1987; 8: 189-191.

10 Nahass RG. Cook S. Weinstein MP. Vertebral osteomyelitis due to Haemophilus aphrophilus: treatment with ceftriaxone. J Infect Dis 1989; 159: 811-812. 


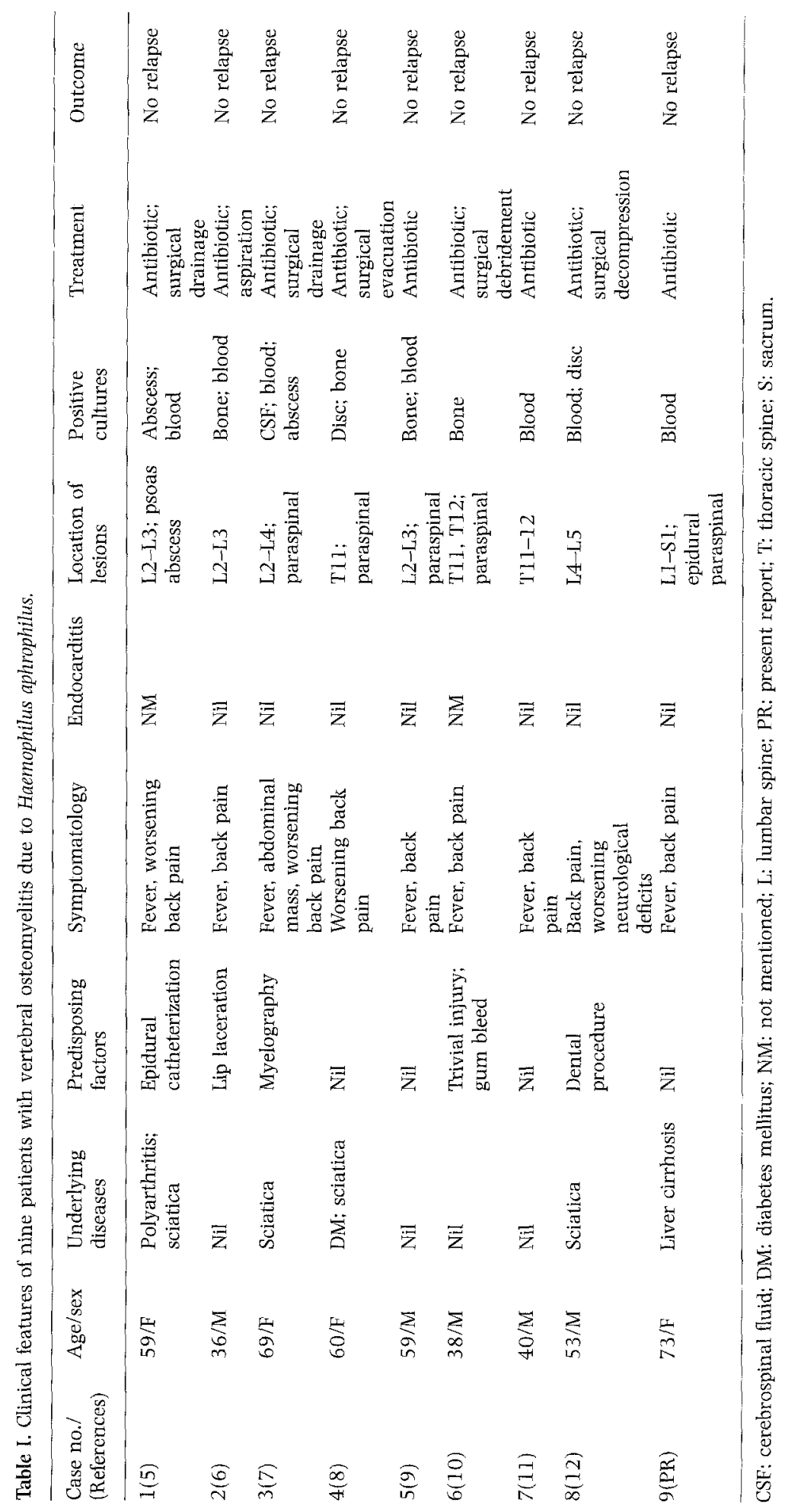


11 Bejuk D, Kuzman I, Soldo I, Kuzmanovic, N, Popovic-Uroic T. Vertebral osteomyelitis caused by Haemophilus aphrophilus. Eur J Clin Microbiol Infect Dis 1993; 12: 643-644.

12 O'Driscoll JC, Keene GS, Weinbren MJ, Johnson AP, Palepou MF, George RC. Haemophilus aphrophilus discitis and vertebral osteomyelitis. Scan J Infect Dis 1995; 27: 291-293.

13 Hand WL. Haemophilus species (including chancroid). In: Mandell GL. Bennett JE, Dolin R, eds. Mandell, Douglas and Bennett's Principles and Practice of Infectious Diseases. New York: Churchill Livingstone, 1995: 2045-2050.
14 Guntheroth WG. How important are dental procedures as a cause of infective endocarditis. Am J Cardiol 1984; 54: 797-801.

15 Danner RL, Hartman BJ. Update of spinal epidural abscess: 35 cases and review of the literature. Rev Infect Dis 1987; 9: 265--274.

16 Darouiche RO. Hamill RJ, Greenberg SB, Weathers SW, Musher DM. Bacterial spinal epidural abscess. Medicine 1992; 71: 369-385.

17 Teman AJ. Spinal epidural abscess. Arch Neurol 1992; 49: 743-746.

18 Baker AS, Ojemann RG, Swartz MN, Richardson EP. Spinal epidural abscess. N Engl J Med 1975; 293: 463-468.

19 Baker AS, Ojemann RG, Baker RA. To decompress or not to decompress - spinal epidural abscess. Clin Infect Dis 1992; 15: 28-29.

\title{
Quinolone-resistant Salmonella paratyphi B Meningitis in a Newborn: a Case Report
}

\author{
Z. A. Bhutta* \\ Department of Paediatrics, The Aga Khan University Medical Center, Karachi, Pakistan
}

\begin{abstract}
While there are concerns about the consequences of widespread use of quinolones, there are few reports of quinoloneresistant strains of Salmonella typhi or Salmonella paratyphi from the Indian subcontinent. We present a case report of a newborn with meningitis due to a quinolone-resistant strain of $S$. paratyphi $B$ presenting to the Aga Khan University Hospital (AKUH).
\end{abstract}

\section{Introduction}

The emergence of multidrug-resistant strains of Salmonella typhi and Salmonella paratyphi in the Indian subcontinent $t^{1.2}$ have posed major problems in the management of these patients, especially in the paediatric age group. Although there are concerns about the use of quinolones in the paediatric age group, ${ }^{3}$ in view of the limited choice of antimicrobial therapy and the prohibitively expensive alternative third generation cephalosporins, quinolones, especially ciprofloxacin, have been widely recommended for use in India for the management of typhoidal salmonellosis in childhood., 5

\section{Case Report}

A 10-day-old female infant was referred to the Aga Khan University Hospital (AKUH) from another city in Northern Pakistan with a history of cyanotic spells and worsening respiratory distress. She was delivered prematurely at 36 weeks' gestation to a gravida mother at a district headquarters hospital (DHQ) by LSCS for preterm labour and intrauterine distress. The mother had no noticeable antenatal problems prior to the onset of premature labour, and had received regular antenatal care. The baby weighed $2.2 \mathrm{~kg}$ at birth and was in a poor condition requiring resuscitation (Apgar score 4 and 2 at 1 and $5 \mathrm{~min}$, respectively). She was placed in an incubator and

* Address correspondence to: Dr Z. A. Bhutta, Department of Paediatrics, The Aga Khan University Hospital, Stadium Road, P.O. Box 3500. Karachi 74800, Pakistan.

Accepted for publication 7 February 1997. given oxygen. She was administered ampicillin and gentamicin at the DHQ hospital and dexamethasone was administered for $48 \mathrm{~h}$. Her respiratory distress improved gradually over the next $48 \mathrm{~h}$, and formula feeds were given. She developed diarrhoea at 4 days of age, and her general condition deteriorated. Only a blood picture and glucose could be performed at this hospital. She was then placed on i.v. ceftriaxone, tobramycin and aminophylline, and when she developed cyanotic spells a request for transfer to Karachi was made. She was air-transferred to the NICU at AKUH at 10 days of age.

At admission to AKUH she weighed $1.7 \mathrm{~kg}$ and was very sick with poor peripheral perfusion, dehydration and respiratory distress (respiratory rate $94 / \mathrm{min}$ ). She was not icteric. The abdomen was distended and both the liver and spleen were palpable $2 \mathrm{~cm}$ below the costal margin. The anterior fontanelle was sunken and there was generalized hypertonia with exaggerated Moro's reflex. Overt seizures were also documented $6 \mathrm{~h}$ after admission. Admission investigations revealed normal blood gases, and oxygen saturation (93\%), haemoglobin $(13.5 \mathrm{~g} / \mathrm{l})$, haematocrit $(39.8 \%)$, white blood cell count $\left(7.5 \times 10^{9} / \mathrm{l}\right)$, platelets $\left(18 \times 10^{12} / \mathrm{l}\right)$, sodium $(129 \mathrm{mmol} / \mathrm{l})$, potassium $(5.8 \mathrm{mmol} / \mathrm{l})$, bicarbonate $(13.6 \mathrm{mmol} / \mathrm{l})$, creatinine $(0.8 \mathrm{mmol} / \mathrm{l})$, BUN $(17 \mathrm{mg} / \mathrm{dl})$, calcium $(8.1 \mathrm{mg} / \mathrm{dl})$, glucose (189 mg/dl), PT (18s, control $13 \mathrm{~s}$ ), PTT (33s, control $35 \mathrm{~s}$ ), FDP $(20 \mu \mathrm{g} / \mathrm{ml})$. Cerebrospinal fluid (CSF) examination revealed turbid fluid with 480 cells $/ \mathrm{mm}^{3}$ (mostly polymorphs), protein $728 \mathrm{mg} / \mathrm{l}$ and glucose of $55 \mathrm{mg} / \mathrm{dl}$. The Gram stain did not reveal any organisms and latex agglutination tests for Escherichia coli, group B streptococcus, pneumococcus, Haemophilus influenza and pseudomonas were negative. Chest X-ray was unremarkable. A contrast computed tomography (CT) scan revealed evidence of generalized meningoencephalitis and 